\title{
Supramolecular Catalysis of Orthoformate Hydrolysis in Basic Solution: An Enzyme-Like Mechanism
}

\author{
Michael D. Pluth, Robert G. Bergman, * and Kenneth N. Raymond*
}

Contribution from the Department of Chemistry, University of California, Berkeley, and Division of Chemical Sciences, Lawrence Berkeley National Laboratory, Berkeley, California, 94720-1460, USA

\section{Corresponding Authors:}

Prof. Robert G. Bergman, Prof. Kenneth N. Raymond, Department of Chemistry, University of California, Berkeley, CA 94720-1460 (USA). Fax: (+1) 510-642-7714 (Bergman). Fax: (+1) 510-486-5283 (Raymond).E-mail: rbergman@berkeley.edu, raymond@ socrates.berkeley.edu 
Abstract A water-soluble self-assembled supramolecular host molecule catalyzes the hydrolysis of orthoformates in basic solution. Comparison of the rate constants of the catalyzed and uncatalyzed reactions for hydrolysis displays rate accelerations of up to 3900 for tri-n-propyl orthoformate. Kinetic analysis shows that the mechanism of hydrolysis with the supramolecular host obeys the Michaelis-Menten model. Mechanistic studies, including ${ }^{13} \mathrm{C}$-labeling experiments, revealed that the resting state of the catalytic system is the neutral substrate encapsulated in the host. Activation parameters for the $k_{\text {cat }}$ step of the reaction revealed that upon encapsulation in the assembly, the entropy of activation becomes more negative in contrast to the uncatalyzed reaction. Furthermore, solvent isotope effects reveal a normal $k\left(\mathrm{H}_{2} \mathrm{O}\right) / k\left(\mathrm{D}_{2} \mathrm{O}\right)$ $=1.6$, confirming that proton transfer is occurring in the transition state and is rate limiting in the catalyzed reaction. In comparison to the uncatalyzed reaction, which operates by an A-1 mechanism in which the decomposition of the protonated substrate is rate limiting, the encapsulated reaction proceeds through an $\mathrm{A}-\mathrm{S}_{\mathrm{E}} 2$ mechanism in which proton transfer from protonated water to the substrate is rate limiting.

\section{Introduction}

Enzymes are able to efficiently carry out a variety of chemical transformations with extraordinary specificity and acceleration over the uncatalyzed process. One class of reactions that enzymes are able to efficiently catalyze are hydrolysis reactions of otherwise hydrolytically stable molecules. For example, DNases are capable of hydrolyzing phosphate diester bonds in DNA within seconds, ${ }^{1-3}$ while under the same conditions, in the absence of enzyme, this hydrolysis has an estimated half-life of 200 million years. ${ }^{4}$ Similarly, enzymatic peptidases are able to cleave peptide bonds quite efficiently with rate accelerations of up to $10^{10}-10^{12}$ when compared to the background hydrolysis under physiological conditions. ${ }^{5-7}$ Inspired by this enzyme-mediated reactivity, synthetic chemists have sought to both explain and emulate such reactivity in synthetic molecular assemblies. Despite the intense study of enzymatic selectivity and efficiency, a complete understanding of how enzymes are able to achieve such heightened reactivity remains elusive. As early as 1946, Linus Pauling suggested that enzymes must preferentially recognize and stabilize the transition state over the ground state of a reaction. ${ }^{8}$ However, Houk and co-workers recently reported a survey of binding affinities in a wide variety of enzyme-ligand, enzyme-transition-state, and synthetic host-guest complexes and found that the average binding affinities were insufficient to generate many of the rate accelerations observed in biological systems. ${ }^{9}$ This suggests that transition-state stabilization alone cannot explain the high reactivity of enzymes, but rather other forces must contribute to the activation of substrate molecules. The nature and magnitude of these forces remains an active area of research. $^{10-15}$

Enzymes have evolved to create elaborate active sites containing precise arrangements of hydrogen-bonding networks, electrostatic interactions, and functional group availability specifically aimed at increasing the reactivity of bound substrates. While the development of synthetic host-guest systems has not reached the level of enzyme specificity, the characteristics of each synthetic assembly, such as the size, shape, charge, and functional group availability, greatly influence the guest-binding characteristics and have led to remarkable and often unexpected reactivity. ${ }^{9,}$ 16-23 For example, the increased local concentration upon encapsulation of substrates for bimolecular reactions has been exploited for enhanced reactivity inside of synthetic hosts. By pre-organizing substrates, supramolecular assemblies are able to catalyze cycloadditions or pericyclic reactions such as Diels-Alder reactions. ${ }^{24-26}$ In addition to often 
large rate accelerations, encapsulation in synthetic host molecules can alter the reactivity of substrates to produce selectivity otherwise not observed in solution. ${ }^{27-30}$

Synthetic chemists have also used assemblies which preferentially encapsulate charged guests to try to emulate the hydrolytic efficiency of enzymes. Other supramolecular systems have demonstrated the ability of the interior cavity or periphery of the host to shift the $\mathrm{p} K_{\mathrm{a}}$ of encapsulated guests by up to $2 \mathrm{p} K_{\mathrm{a}}$ units $^{31-34}$ and we have shown shifts of up to $4.5 \mathrm{p} K_{\mathrm{a}}$ units. $^{35}$ This type of stabilization should also affect the transition states of reactions which have highenergy protonated species on the reaction coordinate. Assemblies able to concentrate solvent molecules inside of the host cavity have been used to accelerate the alcoholysis of alkyl halides with marked size selectivity. ${ }^{36}$ Natural cyclodextrins, such as $\beta$-cyclodextrin, have been used to catalyze the hydrolysis of acetals at neutral $\mathrm{pH}$ presumably by exploitation of the hydrogenbonding network around the periphery of the host. ${ }^{37}$ Similarly, functionalized synthetic cyclodextrins have been used in the hydrolysis of glycosides at physiological $\mathrm{pH}$ with sizeable rate accelerations over the background reaction. ${ }^{38-40}$ The reactivity which has been achieved to date in synthetic molecular hosts exemplifies how simple and defined local environments are able to alter substrate reactivity.

Over the past decade, Raymond and co-workers have used the strategy of self-assembly to develop tetrahedral supramolecular assemblies comprised of the stoichiometry $\mathrm{M}_{4} \mathrm{~L}_{6}(\mathrm{M}=$ $\mathrm{Ga}^{\mathrm{III}}(\mathbf{1}), \mathrm{Al}^{\mathrm{III}}, \quad \mathrm{In}^{\mathrm{III}}, \mathrm{Fe}^{\mathrm{III}}, \mathrm{Ti}^{\mathrm{IV}}, \quad$ or $\mathrm{Ge}^{\mathrm{IV}}, \mathrm{L}=N, N^{\prime}$-bis(2,3-dihydroxybenzoyl)-1,5diaminonaphthalene) (Figure 1). ${ }^{41,42}$ While the 12- overall charge of 1 imparts water solubility, the naphthalene walls of the assembly provide a hydrophobic interior cavity, able to encapsulate guests, which is isolated from the bulk aqueous solution. A wide variety of small neutral and monocationic guests including aliphatic hydrocarbons, ${ }^{43}$ protonated guests, ${ }^{44}$ simple organic cations, ${ }^{45}$ and reactive organometallic complexes ${ }^{46-48}$ have been encapsulated in 1 . Analysis of the mechanism for guest exchange revealed that 1 stays intact during the guest exchange process and that the apertures along the 3 -fold axis of $\mathbf{1}$ dilate to allow for guest ingress and egress. ${ }^{45}$ Using 1 to mediate the reactivity of organometallic guests, both stoichiometric and catalytic reactions have been carried out inside of $\mathbf{1}$ with both size- and stereo- selectivity. ${ }^{46-48}$ Furthermore, $\mathbf{1}$ has been used as a catalyst for the sigmatropic rearrangement of enammonium cations. ${ }^{49}$ We have recently reported the ability of $\mathbf{1}$ to greatly favor the protonated form of encapsulated substrates such as amines, with $\mathrm{p} K_{\mathrm{a}}$ shifts of up to $4.5 \mathrm{p} K_{\mathrm{a}}$ units, and have exploited this stabilization for the catalysis of orthoformates and acetals in basic solution. ${ }^{44,50}$ Herein we expand upon our initial report of orthoformate hydrolysis to include a detailed study of the mechanism of hydrolysis in $\mathbf{1}$.
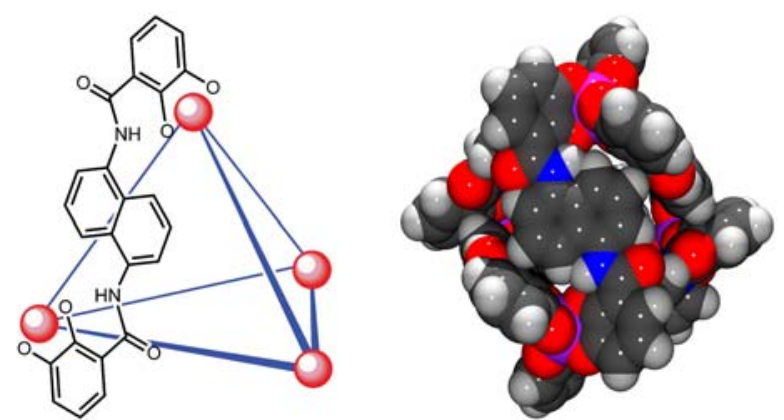

Figure 1. (Left) A schematic representation of 1 with only one ligand shown for clarity. (Right) A space-filling model of $\mathbf{1}$ as viewed down the 2-fold axis defined by the naphthalene-based ligand. 


\section{Results and Discussion}

Reactivity of Neutral Substrates. After our initial report of the reactivity of cationic substrates in the [3,3] sigmatropic rearrangement of enammonium cations, we hoped to expand the catalytic potential of $\mathbf{1}$ by searching for reactions involving neutral substrates which could be catalyzed by $\mathbf{1}$. With the knowledge that both neutral and protonated guests could enter $\mathbf{1}$, and that 1 is able to shift the basicities of encapsulated guests, reactions were sought in which highenergy protonated species could be stabilized upon encapsulation. Many types of acid-catalyzed reactions proceed through mechanisms involving high energy cationic species which potentially can be stabilized by encapsulation in $\mathbf{1}$. Ideally, the final product of the host-mediated hydrolysis would either be more weakly bound than the substrate or be able to undergo further reaction in solution to prohibit further encapsulation, in order to allow for catalytic turnover. An ideal class of hydrolysis reaction are the acid-catalyzed hydrolysis of orthoformates, which are stable in neutral or basic solution but can be hydrolyzed in acidic media to the corresponding formate ester. The mechanism of acid-catalyzed orthoformate hydrolysis is a well-understood process, proceeding by an A-1 mechanism in which the neutral orthoformate is in rapid preequilibrium with the protonated substrate followed by its rate-limiting decomposition. ${ }^{51-53}$ The study of orthoformate hydrolysis has contributed to the mechanistic understanding of hydrolysis reactions in general and was fundamental in the formation of the Brønsted theory of acids almost a century ago. ${ }^{54}$ One advantage of investigating orthoformate hydrolysis by $\mathbf{1}$ in basic solution is that the formate ester product generated from the acid-catalyzed hydrolysis is quickly hydrolyzed to formate anion by base. The anionic formate product is not re-encapsulated in the highly anionic 1, thereby facilitating catalysis and abating product inhibition.

Substrate Scope. In order to test the hypothesis that orthoformates could be catalytically hydrolyzed by $\mathbf{1}$, triethyl orthoformate was added to $\mathbf{1}$ in basic solution. After mild heating, the formation of formate anion and three equivalents of ethanol was observed. In probing the scope of this reaction, a number of small orthoformates were introduced to $\mathbf{1}$ at $\mathrm{pH} 11$ and $50{ }^{\circ} \mathrm{C}$. Small orthoformates able to fit in $\mathbf{1}$ were readily hydrolyzed whereas larger substrates could not enter 1 and remained unreacted (Figure 2). The observed size selectivity is consistent with the finite volume of the cavity of $\mathbf{1}$. By blocking the interior of $\mathbf{1}$ with the strongly binding guest $\mathrm{NEt}_{4}{ }^{+},\left(K_{\mathrm{a}}=10^{4.55(5)} \mathrm{M}^{-1}\right),{ }^{45}$ the catalysis was inhibited. This suggests that the interior cavity of $\mathbf{1}$ is essential in the mediated hydrolysis of orthoformates.

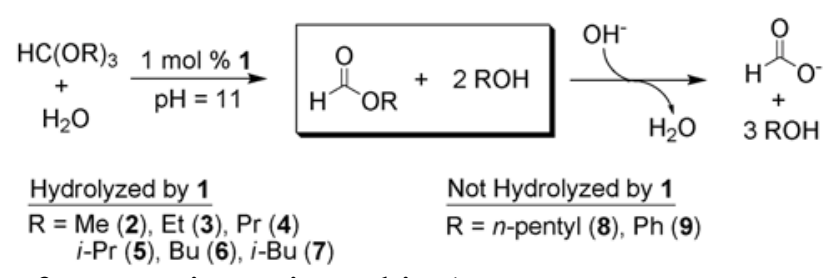

Figure 2. Scope of orthoformates investigated in $\mathbf{1}$.

Typically, upon encapsulation, the NMR resonances of the encapsulated guest are shifted upfield by $2-3 \mathrm{ppm}$ due to the magnetic anisotropy of the naphthalene walls of $\mathbf{1}$. However, during the course of catalysis, no new upfield resonances corresponding to the encapsulated substrate were observed. Under the catalytic conditions, the ${ }^{1} \mathrm{H}$ NMR resonances corresponding to the substrate in solution were significantly broadened but could be sharpened by addition of one equivalent of $\mathrm{NEt}_{4}{ }_{4}$. These data suggest that the encapsulated and free orthoformates are 
exchanging quickly on the NMR timescale. Analysis of the six ${ }^{1} \mathrm{H}$ NMR resonances corresponding to $T$-symmetric $\mathbf{1}$ provided additional information. Upon addition of small orthoformates to $\mathbf{1}$, the $T$-symmetry of $\mathbf{1}$ is maintained, but the ${ }^{1} \mathrm{H}$ NMR resonances shift, thereby suggesting an interaction of the orthoformate with $\mathbf{1}$. All of the orthoformates that undergo 1catalyzed hydrolysis shift the ${ }^{1} \mathrm{H}$ NMR resonances of $\mathbf{1}$. Tripentyl orthoformate, however, which is too large to enter $\mathbf{1}$ and is not catalytically hydrolyzed, does not appreciably perturb the ${ }^{1} \mathrm{H}$ NMR spectrum of the assembly (Figure 3). In order to confirm that the shift in the ${ }^{1} \mathrm{H}$ NMR resonances is not due to interaction of the orthoformates with the exterior of $\mathbf{1}$, triethyl orthoformate was added to an aqueous solution of $\left[\mathrm{NEt}_{4} \subset \mathbf{1}\right]^{11-}$. The ${ }^{1} \mathrm{H}$ NMR resonances corresponding to $\mathbf{1}$ did not shift upon substrate addition, suggesting that the orthoformate is not interacting appreciably with the exterior of $\mathbf{1}$.

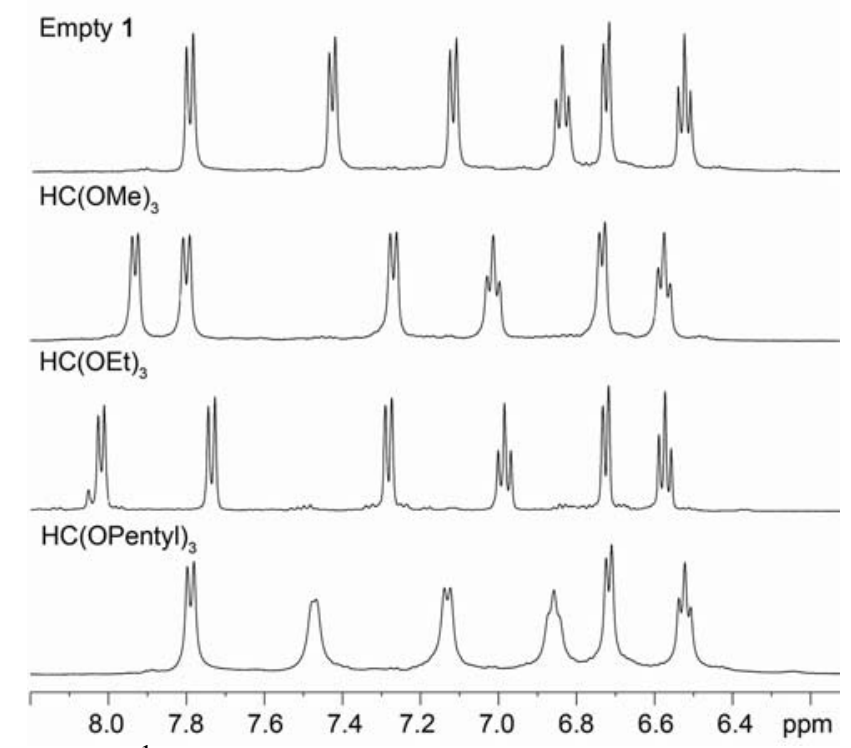

Figure 3. Comparison of the ${ }^{1} \mathrm{H}$ NMR resonances of $\mathbf{1}$ after the addition of various substrates. Substrates which undergo hydrolysis in $\mathbf{1}$ greatly perturb the ${ }^{1} \mathrm{H}$ NMR shifts of $\mathbf{1}$ whereas unreactive substrates do not.

Mechanistic Considerations. The presence of a fast pre-equilibrium involving guest exchange is analogous to the Michaelis-Menten mechanism in which substrate binding is a fast equilibrium before the rate limiting step of the reaction. In order to solidify this analogy, Michaelis-Menten kinetics were explored using $\mathbf{3}$ as the substrate. When the substrate concentration was increased while maintaining constant $\mathrm{pH}$ and concentration of $\mathbf{1}$, substrate saturation was observed that was consistent with the Michaelis-Menten formalism (Figure 4a). 

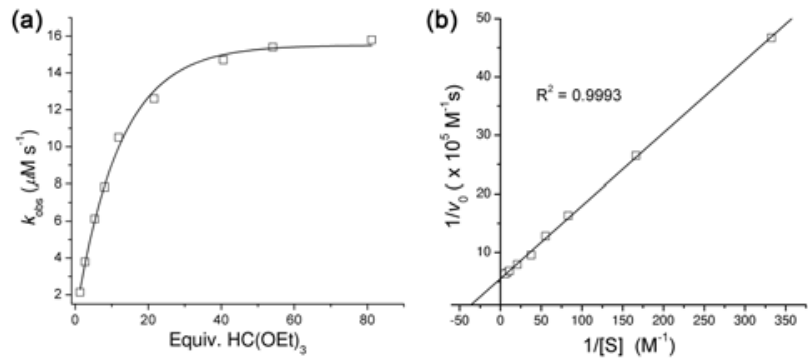

Figure 4. Rate dependence on [3] with catalytic 1 in $\mathrm{H}_{2} \mathrm{O} \mathrm{pH}=11.0,100 \mathrm{mM} \mathrm{K}_{2} \mathrm{CO}_{3}, 50{ }^{\circ} \mathrm{C}$. Substrate saturation (a) is observed. The corresponding Lineweaver-Burke plot (b). Modified from reference 50 .

In order to further elucidate the mechanism of catalysis, the overall rate law was determined. Working under saturation conditions, i.e. pseudo-zeroth-order order in substrate, kinetic analysis showed that the reaction was first-order in both $\left[\mathrm{H}^{+}\right]$and $[\mathbf{1}]$ and both substrate consumption and product formation are pseudo- $0^{\text {th }}$ order as expected (Figure 5). In the stoichiometric reaction, the dependence of the rate on substrate concentration was found to be first order. The combined kinetic data yielded the overall rate law: rate $=k\left[\mathrm{H}^{+}\right][$Substrate $][\mathbf{1}]$, which at saturation reduces to: rate $=k^{\prime}\left[\mathrm{H}^{+}\right][\mathbf{1}]$.

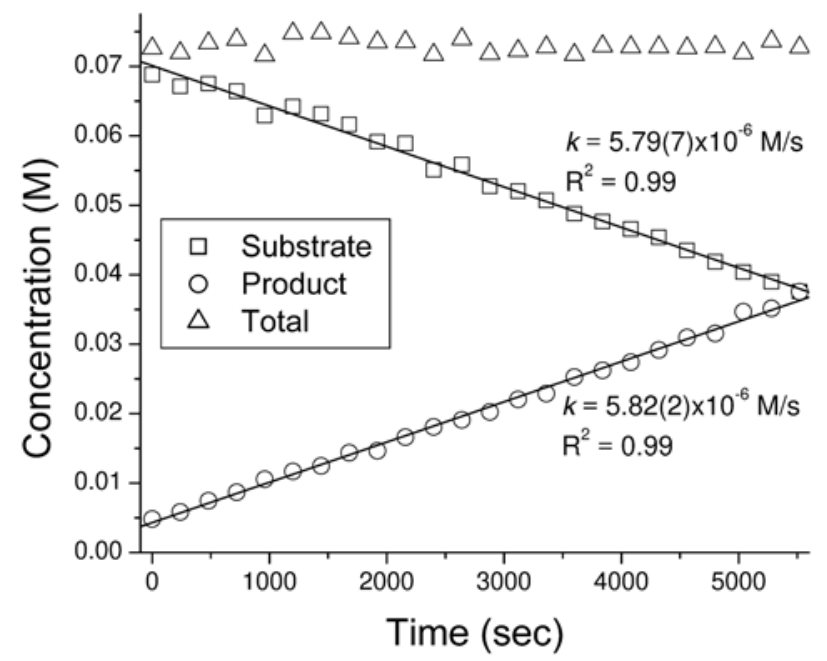

Figure 5. Substrate consumption and product formation are pseudo-zeroth-order in the saturation regime of the catalyzed reaction. Modified from reference 50.

From the data discussed above, we propose that the neutral substrate enters $\mathbf{1}$ to form a hostguest complex, leading to the observed substrate saturation. Based on the ability of $\mathbf{1}$ to encapsulate neutral hydrophobic guests, we surmised that this was the resting state of the catalytic cycle (vide infra). The encapsulated substrate then undergoes protonation followed by two successive hydrolysis steps, liberating two equivalents of the corresponding alcohol and affording the protonated formate ester. Finally, the protonated formate ester is ejected from 1 and further hydrolyzed by base in solution to formate ion. It should be noted that any of the steps after the initial acid catalyzed first step could be catalyzed by either acid or base, so if at any point the substrate escaped the confines of $\mathbf{1}$, it would be quickly converted to product by base in solution. The overall reaction scheme outlined in Figure 6 parallels enzymatic 
Michaelis-Menten kinetics as evidenced by the initial pre-equilibrium involving exchange of the substrate followed by the first-order rate limiting step involving proton transfer from protonated water to the substrate. Each of the individual steps are examined further (vide infra) and all are consistent with the proposed mechanism.

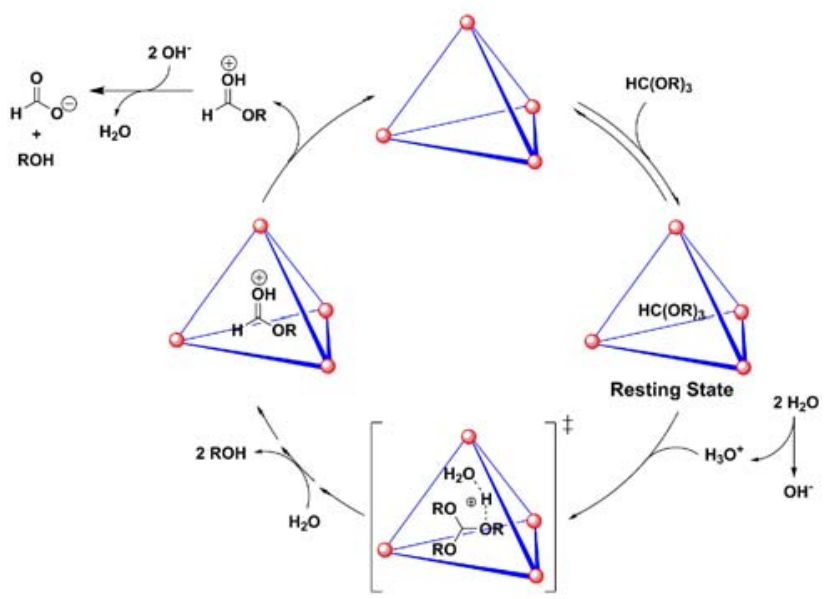

Figure 6. Proposed mechanism for hydrolysis of orthoformates in $\mathbf{1 .}$

Investigation of Steps in the Catalytic Cycle. The initial pre-equilibrium forming the host-guest complex with encapsulated neutral substrate is presumably driven by the hydrophobic effect in which desolvation plays an important driving force for the encapsulation process. If this is the case, the addition of organic solvents to an aqueous solution of $\mathbf{1}$ is expected to retard the reaction by disfavoring the initial encapsulation of the substrate. ${ }^{55}$ In order to probe this hypothesis, a number of organic solvents ( $25 \%$ by volume) such as $d_{3}-\mathrm{MeOH}, d_{6}$-DMSO, $d_{7-}$ DMF, or $d_{8}$-dioxane were added to an aqueous solution of $\mathbf{1}$ under the catalytic conditions. In all cases, the addition of organic solvents greatly reduced the rate of product formation (Figure 7).

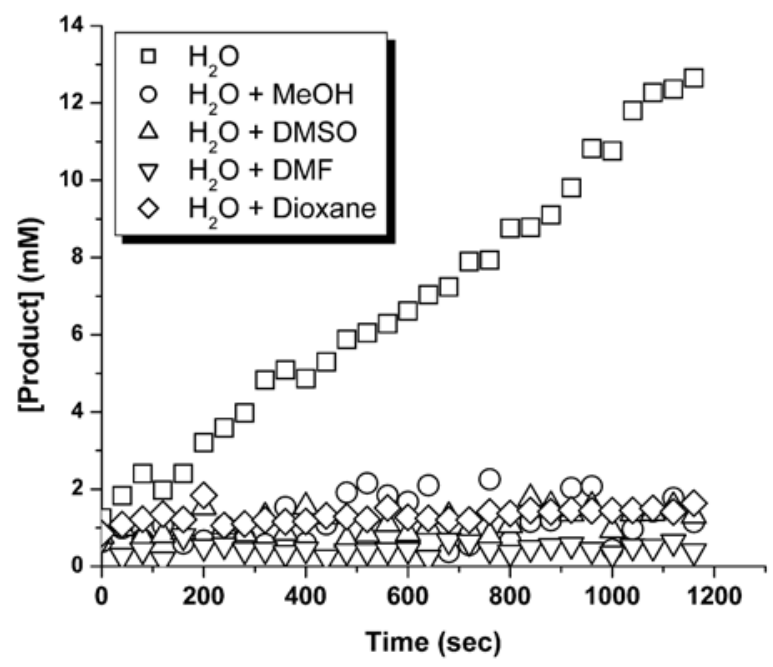


Figure 7. Solvent dependence on the initial rate of hydrolysis for $\mathbf{2}$.

Having established the importance of neutral substrate encapsulation in the catalytic cycle, the resting state of the catalysis was probed. Although the encapsulated guests could not be directly observed under catalytic conditions, greatly increasing the concentration of $\mathbf{1}$ to a near-saturated $(80-100 \mathrm{mM})$ solution followed by addition of a stoichiometric amount of 3 allowed for observation of the 1:1 host-guest complex $[\mathbf{3} \subset \mathbf{1}]^{11-}$ by ${ }^{1} \mathrm{H}$ NMR. In order to probe the identity of the encapsulated species, ${ }^{13} \mathrm{C}$-labeled $\mathrm{H}^{13} \mathrm{C}(\mathrm{OEt})_{3}\left({ }^{13} \mathrm{C}-3\right)$ was used as the substrate. This allowed for differentiation between different possible resting states in the reaction based on the observed ${ }^{13} \mathrm{C}\left\{{ }^{1} \mathrm{H}\right\}$ chemical shift and the ${ }^{1} J_{\mathrm{CH}}$ coupling constant. Possible resting states in the catalytic cycle could include the neutral orthoformate (3), protonated orthoformate $\left(\mathrm{H}^{+} \mathbf{- 3}\right)$, hemiorthocarboxylate $(\mathbf{1 0})$, oxonium $(\mathbf{1 1})$, or the formate ester product (12). In order to compare predicted ${ }^{13} \mathrm{C}\left\{{ }^{1} \mathrm{H}\right\}$ shifts corresponding to the different possible resting states the magnetic tensors were calculated using Gaussian $03^{56}$ at the B3LYP/6-31++G(d,p) level of theory using the Gauge-Independent Atomic Orbital (GIAO) method (Figure 8) for the model complex $2{ }^{57}$ The ${ }^{1} J_{\mathrm{CH}}$ coupling constants reported in Figure 8 were measured from authentic ${ }^{13} \mathrm{C}$ labeled materials.

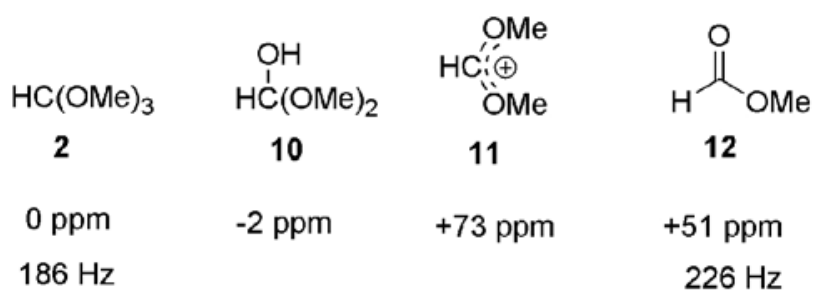

Figure 8. Calculated chemical shifts relative to 2 and experimental ${ }^{1} J_{\mathrm{CH}}$ couplings for possible resting-state species for the catalysis in $\mathbf{1}$.

Under stoichiometric conditions at high concentration, the ${ }^{13} \mathrm{C}\left\{{ }^{1} \mathrm{H}\right\}$ NMR resonance corresponding to ${ }^{13} \mathrm{C}-3$ was shifted from $113.5 \mathrm{ppm}$ to $110.7 \mathrm{ppm}$. This modest $2.8 \mathrm{ppm}$ shift is consistent with the typical range of NMR shifts upon encapsulation in 1 . The ${ }^{13} \mathrm{C}\left\{{ }^{1} \mathrm{H}\right\}$ chemical shift of $110.7 \mathrm{ppm}$, as compared to the $113.5 \mathrm{ppm}$ of unencapsulated ${ }^{13} \mathrm{C}-3$ in $\mathrm{D}_{2} \mathrm{O}$, is most consistent with the neutral substrate as the encapsulated guest. The observed chemical shift eliminates the oxonium and formate ester as possibilities for the resting state, but does not exclude the possibility of 10. However, in the generation of the resting state, no production of ethanol was observed. This eliminates $\mathbf{1 0}$ as a possible resting state. Furthermore, hemiorthocarboxylate $\mathbf{1 0}$ would be extremely sensitive to either acid or base and would be quickly degraded upon ejection from 1. Based on the known fast pre-equilibrium involving substrate exchange, 10 can be further eliminated as a resting state possibility. In order to compare the ${ }^{1} J_{\mathrm{CH}}$ coupling constants of the encapsulated species and the free orthoformate, an equivalent sample was prepared but with eight equivalents of $\mathrm{NEt}_{4}{ }^{+}$to block the interior of 1 . A coupling constant in the ${ }^{13} \mathrm{C}$ NMR spectrum of ${ }^{1} J_{\mathrm{CH}}=186 \mathrm{~Hz}$ was observed, compared with ${ }^{1} J_{\mathrm{CH}}$ $=184 \mathrm{~Hz}$ for the resting state of the encapsulated orthoformate (Figure 9a). This confirms that the labeled carbon did not change hybridization and that the orthoformate is still intact upon encapsulation. Additionally, a 2D HSQC ${ }^{1} \mathrm{H}-{ }^{13} \mathrm{C}\left\{{ }^{1} \mathrm{H}\right\}$ experiment on the encapsulated species 
revealed a cross peak between the ${ }^{13} \mathrm{C}\left\{{ }^{1} \mathrm{H}\right\}$ signal and the formyl $\mathrm{C}-\mathrm{H}$ proton at the expected chemical shift (Figure 9b).

(a)
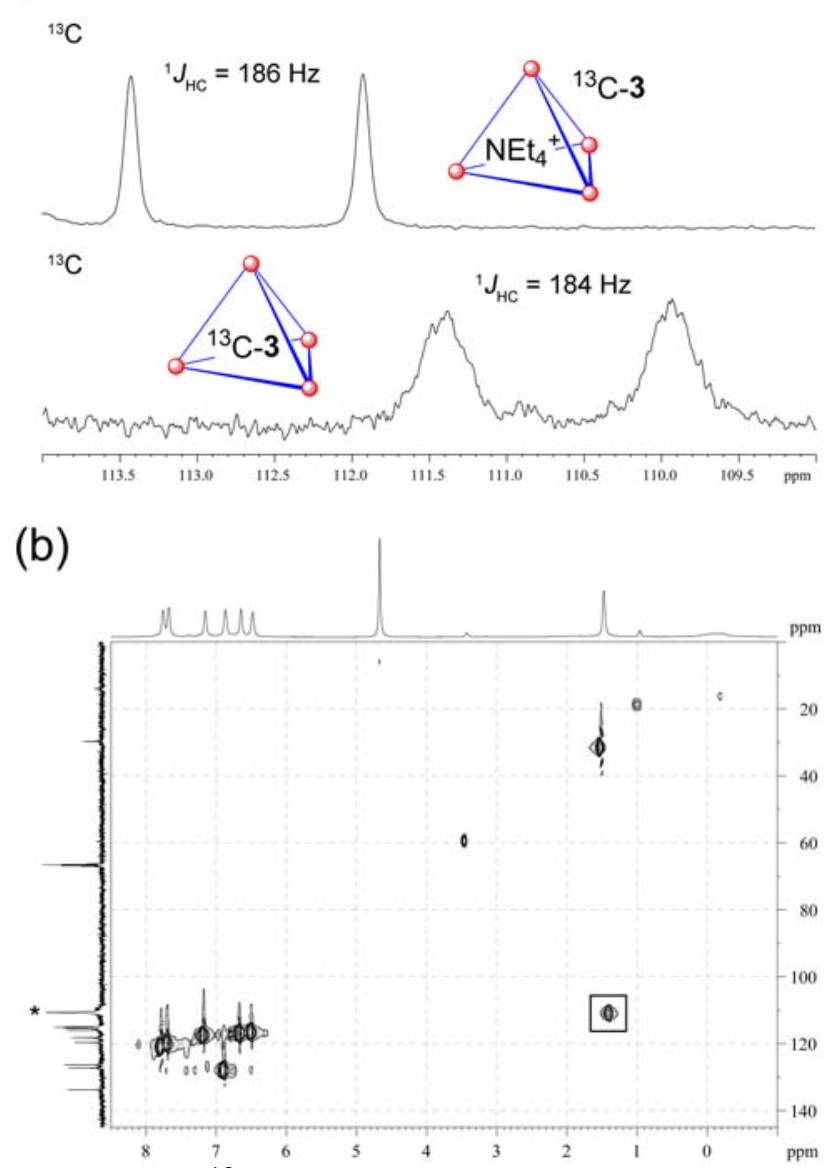

Figure 9. (a) ${ }^{13} \mathrm{C}$ NMR spectrum of ${ }^{13} \mathrm{C}-3$ with $\left(\mathrm{NEt}_{4}\right)_{11}\left[\mathrm{NEt}_{4} \subset \mathbf{1}\right]$ in $\mathrm{D}_{2} \mathrm{O}$ (top), and ${ }^{13} \mathrm{C} \mathrm{NMR}$ spectrum of $\left[{ }^{13} \mathrm{C}-3 \subset \mathbf{1}\right]{ }^{12-}$ in $\mathrm{D}_{2} \mathrm{O}$ (bottom). (b) ${ }^{1} \mathrm{H}-{ }^{13} \mathrm{C}\left\{{ }^{1} \mathrm{H}\right\}$ HSQC NMR spectrum showing correlation between the $\mathrm{C}-\mathrm{H}(*)$ of encapsulated ${ }^{13} \mathrm{C}-3$.

Having established the resting state of the catalytic system, the next step was to probe the nature of the transition state in order to further characterize the rate limiting step. This was accomplished by measuring the activation parameters and solvent isotope effect, $k\left(\mathrm{H}_{2} \mathrm{O}\right) / k\left(\mathrm{D}_{2} \mathrm{O}\right)$, for the $k_{\text {cat }}$ step of the reaction. Both of these kinetic parameters have been used extensively to characterize the transition states of many hydrolysis reactions, including orthoformate hydrolysis. ${ }^{51-53}$ Eyring analysis of $k_{\text {cat }}$ values determined at different temperatures were used to determine the activation parameters for the catalyzed reaction: $\Delta G^{\ddagger}{ }_{298 \mathrm{~K}}=22(2) \mathrm{kcal} / \mathrm{mol}, \Delta H^{\star}=$ $21(1) \mathrm{kcal} / \mathrm{mol}$, and $\Delta S^{\dagger}=-5(1) \mathrm{cal} / \mathrm{mol} \mathrm{K}$. Additionally, measurement of $k_{\text {cat }}$ in normal and deuterated water at $\mathrm{pH}$ (or $\mathrm{pD}) 11.0$ revealed $k_{\text {cat }}\left(\mathrm{D}_{2} \mathrm{O}\right)=5.1 \times 10^{-3} \mathrm{~s}^{-1}$ and $k_{\text {cat }}\left(\mathrm{H}_{2} \mathrm{O}\right)=8.1 \times 10^{-3}$ $\mathrm{s}^{-1}$ thereby affording the normal solvent isotope effect of 1.6 .

In general, the acid catalyzed hydrolysis of orthoformates is thought to proceed through an A-1 mechanism where protonation of the substrate is fast and reversible, and the rate-limiting step is the decomposition of the protonated substrate. ${ }^{51-53}$ These reactions are generally 
characterized by a positive $\Delta S^{\ddagger}$ in the range of $6-10 \mathrm{cal} / \mathrm{mol} \mathrm{K}{ }^{58,59}$ Similarly, since proton transfer is not involved in the rate limiting step, the observed solvent isotope effect is due to the effect of deuteration on the pre-equilibrium and generally ranges from $0.25-0.5$. The solvent isotope effect for the hydrolysis of triethyl orthoformate in aqueous solution ranges from 0.37 0.47 depending on the temperature and experimental details. ${ }^{59-61}$ However, neither the observed activation parameters nor solvent isotope effects for the hydrolysis of $\mathbf{3}$ catalyzed by $\mathbf{1}$ coincide with the kinetic parameters for the background orthoformate hydrolysis reaction. This suggests that the reaction occurring in $\mathbf{1}$ proceeds though a transition state and rate-limiting step that are different from those of the background reaction.

The observed entropy of activation for catalysis in $\mathbf{1}$ of $-5(1) \mathrm{cal} / \mathrm{molK}$ is not consistent with the A-1 mechanism known for orthoformate hydrolysis. The negative activation entropy suggests that the transition state is more ordered than the ground state, suggesting a mechanism in which either attack of the protonated substrate is rate-limiting (A-2 mechanism) or in which proton-transfer from the acid (likely $\mathrm{H}_{3} \mathrm{O}^{+}$) is rate-limiting $\left(\mathrm{A}-\mathrm{S}_{\mathrm{E}} 2\right.$ mechanism). ${ }^{51}$ The solvent isotope effects can be used to differentiate between these two possibilities. For A-2 hydrolysis mechanisms, the nucleophilic attack of solvent on the protonated species is rate limiting and leads to large negative entropies of activation and solvent isotope effects near unity due to the similar nucleophilicity of $\mathrm{OD}_{2}$ and $\mathrm{OH}_{2}$. In $\mathrm{A}-\mathrm{S}_{\mathrm{E}} 2$ hydrolysis mechanisms, the entropies of activation are also negative but proton transfer is rate-limiting. This is evidenced by solvent isotope effects less than unity due to the difference in zero-point energy between $\mathrm{O}-\mathrm{H}$ and O-D bonds. These values are typically approximately 1.7 but can range from $1.3-4.0$. For the hydrolysis catalyzed by $\mathbf{1}$, the solvent isotope effect value of 1.6 is consistent with an A- $\mathrm{S}_{\mathrm{E}} 2$ mechanism for hydrolysis in which proton transfer is occurring in the rate limiting step leading to a transition state as shown in Figure 10.
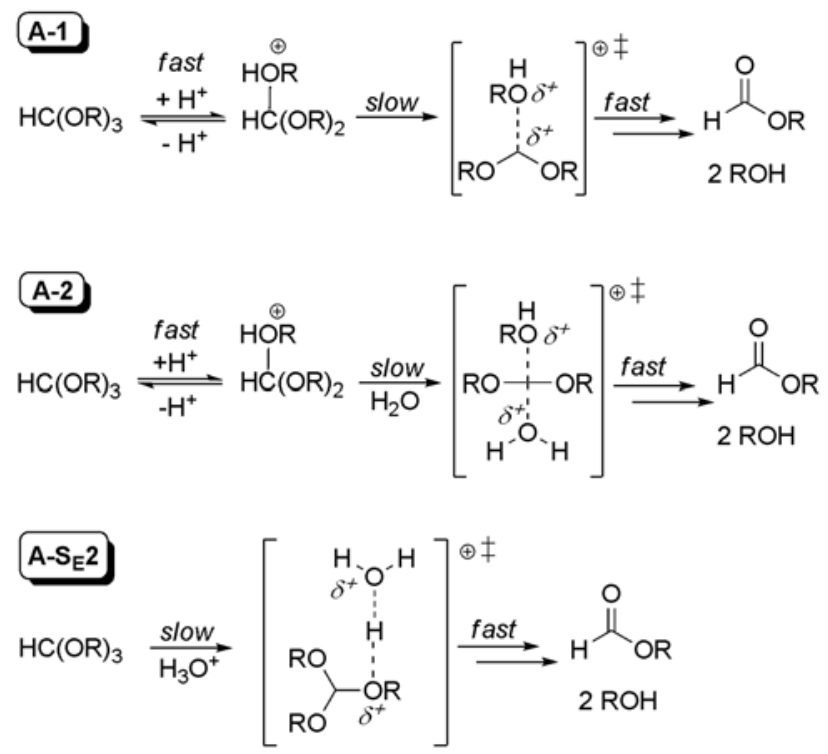

Figure 10. Mechanisms and transition states for A-1, A-2, and A-S 2 orthoformate hydrolysis. Orthoformate hydrolysis in 1 likely occurs through the $\mathrm{A}-\mathrm{S}_{\mathrm{E}} 2$ transition state.

These mechanistic parameters suggest that protonated water is able to enter $\mathbf{1}$ and react with the encapsulated orthoformate. After the rate-limiting proton transfer, the bound water molecule is poised to act as a nucleophile for attack on the protonated substrate. Alternatively, if 
multiple water molecules are concomitantly encapsulated with the substrate in the cavity of $\mathbf{1}$, any of these could act as a nucleophile after the proton transfer step in the hydrolysis reaction. The observed activation parameters and solvent isotope effect suggest that at least the initial hydrolysis step following rate-limiting protonation is occurring inside of $\mathbf{1}$. If, for example, after protonation in $\mathbf{1}$, the substrate were to egress from $\mathbf{1}$ into bulk solution, the observed solvent isotope effect would be greater than unity. Similarly, we have previously shown that hydroxide, which would be a more potent nucleophile than water in the attack of the protonated substrate, is unable to approach the exterior of highly charged $\mathbf{1}$ in aqueous solution. ${ }^{49}$ It should be noted that after the first hydrolysis step, all of the other steps can be either acid or base catalyzed, so ejection of the substrate from 1 after the initial hydrolysis step would quickly lead to formation of the formate product.

Although alkyl orthoformates generally proceed through an A-1 hydrolysis mechanism, orthoformates which are able to more greatly stabilize the carbocation intermediates during the course of the reaction, such as triphenyl orthoformate, are thought to proceed through an A-S 2 mechanism. ${ }^{62}$ In general, as the stability of the carbocations on the reaction coordinate increases, the transition state is moved closer to the reactants and the magnitude of the solvent isotope effect decreases. $^{52,63,64}$ Since the highly anionic $\mathbf{1}$ is able to greatly stabilize cationic guest molecules, the observed shift in mechanism from A-1 to A-S 2 upon encapsulation may be a direct effect of the preference of monocationic guests to be encapsulated in $\mathbf{1}$.

Based on these more detailed kinetic data, the complete catalytic cycle for the hydrolysis reaction is shown in Figure 6. The substrate enters empty 1 to generate the resting state of the catalytic cycle. When $\mathrm{H}_{3} \mathrm{O}^{+}$enters the cavity of $\mathbf{1}$, rate-limiting proton transfer occurs to generate the protonated substrate which is then quickly attacked by water inside of $\mathbf{1}$. After this initial hydrolysis step, subsequent hydrolyses can occur inside of $\mathbf{1}$ to form the formate ester or the intermediate could be ejected into basic solution thereby also forming the formate ester. Upon entering basic solution, the formate ester is quickly hydrolyzed by base to form formate anion and the empty assembly is regenerated.

Analysis of the Rate Law Based on the mechanism outlined for the hydrolysis of orthoformates in $\mathbf{1}$ under alkaline conditions, the overall reaction can be described as in equation (1) where the initial pre-equilibrium is defined by $k_{1}$ and $k_{-1}$ and is followed by the the rate limiting $k_{2}$ proton transfer step (the $k_{\text {cat }}$ measured from Michaelis-Menten kinetics). By applying steady-state analysis to the $[\mathrm{S} \subset \mathbf{1}]$ resting state, the complete rate law can be derived (eq. 2 ).

$$
\begin{aligned}
& \mathrm{S}+\mathbf{1} \frac{k_{1}}{k_{-1}} \mathrm{~S} \subset \mathbf{1} \stackrel{k_{2}\left[\mathrm{H}^{+}\right]}{\longrightarrow} \mathrm{P}+\mathbf{1} \\
& \text { rate }=\frac{k_{1} k_{2}[\mathrm{~S}]\left[\mathrm{H}^{+}\right][\mathbf{1}]_{\mathrm{tot}}}{k_{-1}+k_{1}[\mathrm{~S}]+k_{2}\left[\mathrm{H}^{+}\right]}
\end{aligned}
$$

Based on the derived rate law, the reaction should be first order in the concentration of substrate, proton, and 1, all of which are experimentally observed. Similarly, the reaction should show saturation behavior in both substrate and proton concentration. However, during the experimental determination of the rate law, only substrate saturation is observed. This implies that $k_{1}[\mathrm{~S}] \gg k_{2}\left[\mathrm{H}^{+}\right]$which is consistent with the low concentration of $\left[\mathrm{H}^{+}\right]$present under the reaction conditions. Although no saturation behavior was observed in $\left[\mathrm{H}^{+}\right]$from $\mathrm{pH} 13$ to $\mathrm{pH} 8$, it is possible that at much higher concentrations of $\left[\mathrm{H}^{+}\right]$, saturation behavior could be observed. 
However, $\mathbf{1}$ itself is not stable in acidic media due to protonation of the catechol oxygen atoms. Nonetheless, the derived rate law is consistent with the observed kinetic data since under the reaction conditions it can be further reduced to equation 3 .

$$
\text { rate }=\frac{k_{1} k_{2}[\mathrm{~S}]\left[\mathrm{H}^{+}\right][1]_{\mathrm{tot}}}{k_{-1}+k_{1}[\mathrm{~S}]}
$$

Rate Acceleration In order to compare the rate acceleration of the catalyzed over the uncatalyzed reaction, the $k_{\text {cat }}$ rate constants from Michaelis-Menten studies were compared to the background reaction for hydrolysis (Table 1). This analysis revealed sizeable acceleration in all cases with the largest acceleration being 3900 in the case of $4 .^{65}$ Further analysis of the Michaelis-Menten parameters revealed a number of trends. Assuming a fast pre-equilibrium for guest encapsulation with respect to $k_{\text {cat }}$, then $\mathrm{K}_{\mathrm{M}} \sim \mathrm{K}_{\mathrm{d}}$, which allows for comparison of the binding affinities of different substrates in 1. As the hydrophobicity of the orthoformate increases, the binding affinity of the substrate increases, consistent with the hydrophobic effect driving encapsulation. Of the substrates investigated, the two propyl isomers (4 and 5) show the highest affinity for $\mathbf{1}$, with triisopropyl orthoformate being more tightly bound that tri-n-propyl orthoformate. Although $\mathbf{4}$ and $\mathbf{5}$ have similar sizes, encapsulation of $\mathbf{4}$ in $\mathbf{1}$ results in a greater loss of conformational freedom than encapsulation of the more compact 5 . The enhanced binding of 5 may explain why the rate acceleration is attenuated when compared to 4 . Comparison of $k_{\text {cat }} / \mathrm{K}_{\mathrm{M}}$ for the different substrates, often referred to as the specificity factor, allows for comparison of the second-order proportionality constant for the rate of conversion of pre-formed host-substrate complex to product, thereby providing a comparison of how efficiently different substrates can compete for the active site of 1. As the size of the substrate increases, the specificity increases to a maximum for $\mathbf{4}$ and then decreases for $\mathbf{5}$. For substrates such as $\mathbf{4}$, a balance between hydrophobicity and steric size makes it an ideal fit for $\mathbf{1}$ and this is reflected by the highest specificity factor and the highest rate acceleration in comparison to the background reaction. The catalytic proficiency $\left(\left(k_{\text {cat }} / \mathrm{K}_{\mathrm{M}}\right) / k_{\text {uncat }}\right)$ for different substrates is a good measure of how encapsulation affects the transition state stabilization with respect to the uncatalyzed reaction,. For substrates $\mathbf{2 - 4}$, as the alkyl chain lengthens, the catalytic proficiency increases, suggesting that a more optimal fit for the transition state in $\mathbf{1}$ is achieved for the larger substrates. Although substrates $\mathbf{4}$ and $\mathbf{5}$ have similar catalytic proficiencies, $\mathbf{4}$ shows a much higher rate acceleration, which is likely due to the greater stabilization of encapsulated $\mathbf{5}$. This is consistent with the notion that both ground state and transition state effects can play an active role in the catalysis inside of the supramolecular host.

Table 1. Tabulation of kinetic parameters for hydrolysis of orthoformates in $\mathbf{1}$ at $50{ }^{\circ} \mathrm{C}, \mathrm{pH}=$ 11.0 .

\begin{tabular}{cccccccc}
\hline Substrate & $\begin{array}{c}\boldsymbol{V}_{\text {max }} \\
\left(\mathbf{M ~ s}^{-1}\right)\end{array}$ & $\begin{array}{c}\mathbf{K}_{\mathbf{M}} \\
(\mathbf{m M})\end{array}$ & $\begin{array}{c}\boldsymbol{k}_{\text {cat }} \\
\left(\mathbf{s}^{-1}\right)\end{array}$ & $\begin{array}{c}\boldsymbol{k}_{\text {uncat }} \\
\left(\mathbf{s}^{-1}\right)\end{array}$ & $\begin{array}{c}\boldsymbol{k}_{\text {cat }} / \mathbf{K}_{\mathbf{M}} \\
\left(\mathbf{M}^{-1} \mathbf{s}^{-1}\right)\end{array}$ & $\begin{array}{c}\left(\boldsymbol{k}_{\text {cat }} / \mathbf{K}_{\mathbf{M}}\right) / \boldsymbol{k}_{\text {uncat }} \\
\left(\mathbf{M}^{-1}\right)\end{array}$ & $\boldsymbol{k}_{\text {cat }} / \boldsymbol{k}_{\text {uncat }}$ \\
\hline $\mathbf{2}$ & $1.3 \times 10^{-5}$ & 24.0 & $5.7 \times 10^{-3}$ & $3.7 \times 10^{-5}$ & 0.238 & $6.4 \times 10^{3}$ & 150 \\
$\mathbf{3}$ & $1.8 \times 10^{-5}$ & 21.5 & $8.1 \times 10^{-3}$ & $1.4 \times 10^{-5}$ & 0.275 & $1.9 \times 10^{4}$ & 560 \\
$\mathbf{4}$ & $4.0 \times 10^{-5}$ & 19.6 & $1.8 \times 10^{-2}$ & $4.6 \times 10^{-6}$ & 0.918 & $2.0 \times 10^{5}$ & 3900 \\
$\mathbf{5}$ & $9.2 \times 10^{-6}$ & 7.69 & $3.9 \times 10^{-3}$ & $4.3 \times 10^{-6}$ & 0.502 & $1.2 \times 10^{5}$ & 890 \\
\hline
\end{tabular}




\section{Conclusions}

In summary, we have expanded our study of catalytic hydrolysis of orthoformates mediated by a supramolecular assembly to include a detailed kinetic analysis of the mechanism of catalysis. The initial encapsulation of the neutral substrate is driven by the hydrophobic effect as shown by mixed solvent studies and ${ }^{13} \mathrm{C}$ labeling experiments. Upon encapsulation, the observed entropy of activation and solvent isotope effect suggest that the initial step of the hydrolysis proceeds through an $\mathrm{A}-\mathrm{S}_{\mathrm{E}} 2$ mechanism which is different from the A-1 mechanism for orthoformate hydrolysis in bulk solution. Kinetic analysis of the rate constants of the catalyzed and uncatalyzed reactions show that the assembly is able to efficiently catalyze the hydrolysis, with rate accelerations of over $10^{3}$; which are among the highest catalytic rate accelerations that have been observed in synthetic supramolecular systems.

\section{Experimental}

General Procedures. All NMR spectra were obtained using an AV-500 MHz spectrometer at the indicated frequencies. The temperature of all variable temperature NMR experiments was calibrated with an ethylene glycol standard. NMR spectra measured in $\mathrm{H}_{2} \mathrm{O}$ were obtained using the Watergate solvent suppression sequence.

Materials. Orthoformates were either purchased from a commercial supplier or prepared by alcoholysis of triethyl orthoformate and fractionally distilled through a 12-inch Vigreux column followed by distillation over powdered $3 \AA$ molecular sieves. All orthoformates were stored under $\mathrm{N}_{2}$ until use. Carbon-13 labeled triethylorthoformate was purchased from Cambridge Isotope Laboratories and used as received. The host assembly $\mathrm{K}_{12}\left[\mathrm{Ga}_{4} \mathrm{~L}_{6}\right]$ was prepared as described in the literature and precipitated with either acetone or ether.

General Procedure for Kinetics Runs. In an $\mathrm{N}_{2}$-filled glove box, 1 was weighed into a $20 \mathrm{~mL}$ scintillation vial at which point $\mathrm{H}_{2} \mathrm{O}$ buffered to the desired $\mathrm{pH}$ and an internal standard (DMSO) were added. The stock solution was divided into NMR tubes in $500 \mu \mathrm{L}$ aliquots. All kinetic runs with 1 were performed in the probe by allowing the NMR tube to equilibrate at the desired temperature for 10 minutes at which point the tube was ejected, the substrate injected to the tube, and the tube reinserted into the NMR instrument. All Michaelis-Menten kinetic data were fit directly to the Michaelis-Menten equation using non-linear least squares refinement.

Acknowledgment. We thank Dr. Dennis Leung, Dr. Gojko Lalic and Courtney Hastings for helpful discussions, and Dr. Herman van Halbeek and Rudi Nunlist for NMR assistance. This work was supported by the Director, Office of Science, Office of Basic Energy Sciences, and the Division of Chemical Sciences, Geosciences, and Biosciences of the U.S. Department of Energy at LBNL under Contract No. DE-AC02-05CH11231 and an NSF predoctoral fellowship to M.D.P.

Supporting Information Available: Kinetic data, Eyring plots, full citation for reference 56. This material is available free of charge via the Internet at http://pubs.acs.org.

\section{References}

(1) Chin, J., Acc. Chem. Res. 1991, 24, 145-152.

(2) Uhlenbeck, O. C., Nature 1987, 328, 596-600.

(3) Zoug, A. J.; Michael, D. B.; Cech, T. R., Nature 1986, 324, 429.

(4) Chin, J.; Banaszczyk, M., J. Am. Chem. Soc. 1989, 111, 4103-4105.

(5) Bryant, R. A. R.; Hansen, D. E., J. Am. Chem. Soc. 1996, 118, 5498-5499.

(6) Radzicka, A.; Wolfenden, R., Science 1995, 267, 90-93. 
(7) Radzicka, A.; Wolfenden, R., J. Am. Chem. Soc. 1996, 118, 6105-6109.

(8) Pauling, L., Chemical \& Engineering News 1946, 24, 1375 - 1377.

(9) Houk, K. N.; Leach, A. G.; Kim, S. P.; Zhang, X., Angew. Chem. Int. Ed. 2003, 42, 4872 $-4897$.

(10) Benkovic, S. J.; Hammes, G. G.; Hammes-Schiffer, S., Biochemistry 2008, 47, 33173321.

(11) Meyer, M. P.; Tomchick, D. R.; Klinman, J. P., Proc. Nat. Acad. Sci. USA 2008, 105, 1146-1151.

(12) Frauenfelder, H., Nat. Chem. Biol. 2008, 4, 21-22.

(13) Bruice, T. C., Chem. Rev. 2006, 106, 3119-3139.

(14) Warshel, A.; Sharma, P. K.; Kato, M.; Xiang, Y.; Liu, H., Chem. Rev. 2006, 106, 32103235.

(15) Olsson, M. H. M.; Parson, W. W.; Warshel, A., Chem. Rev. 2006, 106, 1737-1756.

(16) Biros, S. M.; Rebek, J., Jr., Chem. Soc. Rev. 2007, 36, 93 - 104.

(17) Oshovsky, G. V.; Reinhoudt, D. N.; Verboom, W., Angew. Chem. Int. Ed. 2007, 46, $2366-2393$.

(18) Pluth, M. D.; Raymond, K. N., Chem. Soc. Rev. 2007, 36, 161-171.

(19) Schmuck, C., Angew. Chem. Int. Ed. 2007, 46, 5830 - 5833.

(20) Yoshizawa, M.; Fujita, M., Pure and Applied Chemistry 2005, 77, 1107 - 1112.

(21) Vriezema, D. M.; Aragonès, M. C.; Elemans, J. A. A. W.; Cornelissen, J. J. L. M.;

Rowan, A. E.; Nolte, R. J. M., Chem. Rev. 2005, 105, 1445 -1490.

(22) Das, S.; Brudvig, G. W.; Crabtree, R. H., Chem. Commun. 2008, 413.

(23) Koblenz, T. S.; Wassenaar, J.; Reek, J. N. H., Chem. Soc. Rev. 2008, 37, 247-262.

(24) Kang, J. M.; Hilmersson, G.; Santamaria, J.; Rebek, J., Jr., J. Am. Chem Soc. 1998, 120, 3650 - 3656 .

(25) Kang, J. M.; Rebek, J., Jr., Nature 1997, 385, 50 - 52.

(26) Kang, J. M.; Santamaria, J.; Hilmersson, G.; Rebek, J., Jr., J. Am. Chem Soc. 1998, 120, 7389 - 7390.

(27) Nishioka, Y.; Yamaguchi, T.; Yoshizawa, M.; Fujita, M., J. Am. Chem Soc. 2007, 129, $7000-7001$.

(28) Yoshizawa, M.; Tamura, M.; Fujita, M., Science 2006, 312, 251 - 254.

(29) Yamaguchi, T.; Fujita, M., Angew. Chem. Int. Ed. 2008, 47, 2067-2069.

(30) Shenoy, S. R.; Crisóstomo, F. R. P.; Iwasawa, T.; Rebek, J., Jr., J. Am. Chem. Soc. 2008, 130, 5658-5659.

(31) Bakirci, H.; Koner, A. L.; Schwarzlose, T.; Nau, W. M., Chem. Eur. J. 2006, 12, 47994807.

(32) Marquez, C.; Nau, W. M., Angew. Chem. Int. Ed. 2001, 40, 3155-3160.

(33) Mohanty, J.; Bhasikuttan, A. C.; Nau, W. M.; Pal, H., J. Phys. Chem. B. 2006, 110, 5132-5138.

(34) Zhang, X.; Gramlich, G.; Wang, X.; Nau, W. M., J. Am. Chem. Soc. 2002, 124, 254-263.

(35) Pluth, M. D.; Bergman, R. G.; Raymond, K. N., J. Am. Chem. Soc. 2007, 129, 1145911467.

(36) Ryu, E.-H.; Cho, H. K.; Zhao, Y., Org. Lett. 2007, 9, 5147-5150.

(37) Krishnaveni, N. S.; Surendra, K.; Reddy, M. A.; Nageswar, Y. V. D.; Rao, K. R., J. Org. Chem. 2003, 68, 2018. 
(38) Ortega-Caballero, F.; Rousseau, C.; Christensen, B.; Petersen, T. E.; Bols, M., J. Am. Chem. Soc. 2005, 127, 3238-3239.

(39) Ortega-Caballero, F.; Bols, M., Can. J. Chem. 2006, 84, 650-658.

(40) Bjerre, J.; Nielsen, E. H.; Bols, M., Eur. J. Org. Chem 2008, 4, 745-752.

(41) Caulder, D. L.; Powers, R. E.; Parac, T. N.; Raymond, K. N., Angew. Chem. Int. Ed. 1998, 37, 1840-1843.

(42) Caulder, D. L.; Raymond, K. N., Acc. Chem. Res. 1999, 32, 975-982.

(43) Biros, S. M.; Bergman, R. G.; Raymond, K. N., J. Am. Chem Soc. 2007, 129, $12094-$ 12095.

(44) Pluth, M. D.; Bergman, R. G.; Raymond, K. N., Angew. Chem. Int. Ed. 2007, 119, 87418743.

(45) Davis, A. V.; Raymond, K. N., J. Am. Chem. Soc. 2005, 127, 7912-7919.

(46) Leung, D. H.; Bergman, R. G.; Raymond, K. N., J. Am. Chem. Soc. 2006, 128, 9781 9797.

(47) Leung, D. H.; Bergman, R. G.; Raymond, K. N., J. Am. Chem. Soc. 2007, 129, 27462747.

(48) Leung, D. H.; Fiedler, D.; Bergman, R. G.; Raymond, K. N., Angew. Chem. Int. Ed. 2004, 43, 963-966.

(49) Fiedler, D.; van Halbeek, H.; Bergman, R. G.; Raymond, K. N., J. Am. Chem. Soc. 2006, $128,10240-10252$.

(50) Pluth, M. D.; Bergman, R. G.; Raymond, K. N., Science 2007, 316, 85-88.

(51) Bell, R. P., The Proton in Chemistry. 2 ed.; Cornell University Press: Ithica, New York, 1973.

(52) Cordes, E. H.; Bull, H. G., Chem. Rev. 1974, 74, 581.

(53) Cordes, E. H., Progr. Phys. Org. Chem. 1967, 4, 1.

(54) Bronsted, J. N.; Wynne-Jones, W. F. K., Trans. Faraday Soc. 1929, 25, 59.

(55) Breslow, R., Acc. Chem. Res. 1991, 24, 159-164.

(56) Frisch, M. J., et al. Gaussian 03, Revision D.01, Gaussian, Inc.: Wallingford CT, 2004.

(57) Trimethyl orthoformate was chosen as a model substrate due to the limited degrees of freedom when compared to triethyl orthoformate.

(58) Koskikullio, J.; Whalley, E., Trans. Faraday Soc. 1959, 66, 809.

(59) Brescia, F.; LaMer, V. K., J. Am. Chem. Soc. 1940, 62, 612.

(60) Horiiel, J. C.; Butler, J. A. V., J. Chem. Soc. 1936, 1361.

(61) Brescia, F.; LaMer, V. K., J. Am. Chem. Soc. 1938, 60, 1962.

(62) Price, M. L.; Adams, J.; Lagenaur, C.; Cordes, E. H., J. Org. Chem. 1969, 34, 22-25.

(63) Hammond, G. S., J. Am. Chem. Soc. 1955, 77, 334-338.

(64) Thornton, E. R., J. Am. Chem. Soc. 1967, 89, 2915-2927.

(65) The low water solubility of tributyl orthoformate and triisobutyl orthoformate prohibited saturation studies for Michaelis-Menten analysis. 